\title{
Vivir y estudiar en las villas del sur global: modulaciones gerenciales de las biopolíticas de la vida urbana
}

\section{Viver e estudar nas favelas do Sul global: modulações gerenciais das biopolíticas da vida urbana}

\section{Living and studying in the urban slums of the global south: modulations of the biopolitics of urban life in management times}

\author{
Silvia Grinberg*
}

\begin{abstract}
RESUMEN
Este artículo tiene por objeto debatir, a través de los resultados de la investigación realizada en la intersección escuela-barrio en la Región Metropolitana de Buenos Aires, algunas líneas que caracterizan los actuales modos de producción política de la vida en su intersección con la vida escolar. Proponemos que el sistema operativo que define a lo urbano involucra su creación como escenario biopolítico en sí; esto es la ciudad como expresión y realización del despliegue de regularización de la vida. Foucault se ocupa de este problema en varios de sus textos y es una cuestión que puede rastrearse desde sus primeras obras hasta las últimas pero que, claramente, desarrolla cuando se ocupa de las nociones de biopolítica y gubernamentalidad. Por medio del trabajo de investigación en escuelas emplazadas en aquellos espacios urbanos comúnmente llamados villas miseria, villa, chabolas o slums, problematizamos algunas de las modulaciones y estatificaciones que
\end{abstract}

DOI: $10.1590 / 0104-4060.53863$

* Universidad Nacional de San Martin. Consejo Nacional de Investigaciones Científicas y Técnicas. Buenos Aires, Argentina. Godoy Cruz 2290 (C1425FQB) CABA. E-mail: grinberg. silvia@gmail.com 
atraviesan a la producción y conducción política de la vida en ese lugar de encuentro con la escolaridad. A modo de hipótesis señalamos que, en los actuales tiempos gerenciales, hacer-hacerse vivir devino modulación clave del ejercicio del poder que, descansando sobre sí mismo, dirime la cuestión del no gobernar demasiado pero tampoco demasiado poco.

Palabras clave: Escolarización. Biopolíticas. Villas. Estratos y modulaciones.

\title{
RESUMO
}

Este artigo tem como objetivo discutir e caracterizar, por meio dos resultados da pesquisa na intersecção escola-bairro na região metropolitana de Buenos Aires, os modos atuais de produção política da vida em sua interseção com a vida escolar. Propomos que o sistema operacional que define o urbano envolva um cenário biopolítico em si: a cidade como expressão e realização do desenvolvimento da regularização da vida. Foucault lida com esse problema em vários de seus textos e é uma questão que pode ser rastreada em suas primeiras obras até as últimas, mas que se desenvolve claramente quando ele aborda as noções de biopolítica e governamentalidade. Através do trabalho de pesquisa nas escolas localizadas nos espaços urbanos do sul global, comumente chamados favelas, vilas ou assentamentos se problematizam algumas das modulações da produção e conduta política da vida. A título de hipótese, destacamos que, nos atuais tempos gerenciais, o faça você mesmo se torna uma modulação chave do exercício do poder que esclarece a máxima de não governar demasiado, tampouco demasiado pouco.

Palavras-chave: Escolarização. Biopolíticas. Vilas. Estratos e modulações.

\begin{abstract}
On the basis of field work conducted in the periphery of the Buenos Aires metropolitan area, this article discusses some of the lines that characterize current modes of political production of life in the intersection with school life. We propose that the operating system that defines the urban involves biopolitics as its scenario: the city as an expression and realization of regularization of life. Foucault deals with this problem in several of his texts and it is a question that can be traced on his first works but, clearly, it is developed when he deals with the notions of biopolitics and governmentality. Through research work in schools located in urban areas called villas miseria, favelas, chavolas or slums, we problematize some of the modulations and stratifications of the production and political conduction of life in current societies. By way of hypothesis, we point out that the self-make live became a key modulation of the exercise of power in the present managerial times,
\end{abstract}


which, located on the itself, diminishes the question of not governing too much but not too little.

Keywords: Schooling. Biopolitics. Slums. Strata and Modulations.

\section{Introducción}

Tanto la pregunta por la vida urbana como la interrogación por el devenir de la escolaridad contemporánea, aunque por motivos probablemente muy diferentes, han adquirido especial centralidad en las últimas décadas. Aquí nos ocupamos de esa intersección, procurando tensionar los actuales modos de producción política de la vida. A través del trabajo de investigación que estamos desarrollando en esos espacios de la urbe metropolitana, donde se condensan pobreza y degradación ambiental - comúnmente llamados villas miseria, favelas, chavolas o slums -, procuraremos describir algunas de las modulaciones que (se) ensamblan las políticas sobre la vida en las sociedades contemporáneas. Por medio de ese acoplamiento escuela-barrio, nos ocupamos de esas modulaciones en ese particular espesor, que involucra a estos barrios que constituyen uno de los modos más notables del crecimiento de las metrópolis del sur global desde fines del siglo pasado. En estos espacios convergen líneas de fuerza que dibujan parte de nuestros contemporáneos modos de vida, donde lo urbano es algo más que un detalle que se anexa a la descripción de nuestra socialidad. La vida contemporánea puede ser pensada como un continuo urbano, donde los barrios más pobres no sólo no son un dato, sino que constituyen el signo más claro de las biopolíticas contemporáneas en el sur globalizado, sus estratos, sedimentaciones y líneas de fuerza.

$\mathrm{Al}$ respecto, cabe señalar que, si las posiciones sociales solían ser pensadas en términos de su posición en el marco de las relaciones de producción, o, desde otras miradas en el marco del mercado de trabajo y el aparato de producción, cuando nos referimos a las villas esta mirada se complejiza. Ello porque, entre muchas otras cuestiones, en las villas convive población que nunca tuvo un empleo, que vive de planes, en la informalidad, el trabajo precario, las changas, etc., como también obreros que trabajan en el mercado formal, ya sea como albañiles o como empleados de servicios de muy diverso tipo. De manera que aquello que distingue a la población que vive en estos emplazamientos es la posición social, geopolítica, de las villas en la urbe metropolitana donde se combinan múltiples aspectos que refieren a la absoluta precaridad (Butler, 2010) de la vida en estos espacios de la urbe. 
Así, la cuestión urbana adquiere especial espesor en este operativo que, como señala Choay (2009), involucra su creación como escenario político, expresión y realización del despliegue de regularización de la vida en sí. Foucault se ocupa de esta cuestión en varios de sus textos y puede rastrearse desde sus primeras obras. Ello, a la vez que, claramente, se despliega cuando desarrolla las nociones de biopolítica y gubernamentalidad. Entre la noción de biopolítica y los crecientes procesos de urbanización de la vida es posible identificar mucho más que una coincidencia histórica. Se trata, más bien, de un conjunto de problemas, saberes y políticas que se crean mutuamente. Desde ya, en el presente asumen nuevas y diferentes notas que son las que aquí nos ocupan.

En el siglo XXI estamos viviendo una tercera o, quizá, la cuarta saga de esta historia donde ahora el territorio ya no es el reino, el cual se ha urbanizado y los flujos se volvieron globales. Vivimos tiempos donde el afuera de la urbe quedó dentro; salir en automóvil de una ciudad implica transitar un continuo que nos interroga por sus límites, por un afuera que va quedando dentro. Ello como parte de ese proceso de urbanización del territorio donde el campo se urbaniza no sólo porque crece el espacio que ocupa la urbe, sino porque la vida en el campo deviene urbana en sí. La pregunta por la ciudad, por la biohistoria (Foucault, 1999) supone una historia de nuestro presente, de nuestros modos de habitar y hacer la urbe o, de acuerdo con Soja (2008) posmetropolis.

Así, proponemos dos procesos paralelos como un modo de acercarnos a una genealogía de nuestros actuales modos de vida. Una mirada que se pregunta por los trazos de constitución de nuestra (pos)moderna vida urbana tendiente a preguntarse por los actuales modos, las rupturas y continuidades. Encontrarnos con los modos de constitución de nuestra actualidad (como lo son el miedo y pánico urbano, la contaminación o la gestión de la pobreza) es una parte de la tarea. La otra consiste en acercarse a las rupturas contemporáneas en los modos de problematización de lo urbano, las tecnologías que se despliegan como modos de actuar sobre ellos. Ello porque, si bien es frecuente referir a la inseguridad como un tema de época, es clave entender que no se trata de un fenómeno sui generis. Probablemente lo sean algunas de las formas noveles que presenta la regulación de la vida. Si en el siglo XIX, la regulación de la vida y la vara de la normalidad definía la acción política, hoy estamos muy cerca y muy lejos de ello. Desde fines del pasado siglo, emprendedorismo y empoderamiento se volvieron los enunciados rectores de nuestra socialidad; enunciados que no dejan de estar atravesados por unos ya no tan nuevos modos del gobierno que responden a la pregunta "¿Puede haber una crisis de 'no gobernar suficiente' en la que el Estado ha fracasado como regulador y que requiere intervención directa de los estados actuando solos o juntos?" (Dean, 2010, p. 463). Ambos enunciados constituyen modulaciones del gobierno de la población que se mue- 
ven entre "demasiado gobierno y muy poco" que, como Dean señala, no deja de enfrentarse a su propia crisis. Los modos de una intervención que, mientras quedamos librados a la propia suerte, generan mecanismos que se presentan en las lógicas de inclusión y los derechos ${ }^{1} ; \mathrm{y}$ constituyen modos particulares de las políticas sobre la vida, que cada vez más modulan cómo hacer hacerse vivir.

En el caso que nos ocupa, las villas son ubicadas y pensadas en el espacio como áreas urbanas abyectas, zonas de inhabitabilidad que, como fantasma, amenaza la producción de subjetividad, así como el bienestar de lo metropolitano. La "gestión de lo social" adquiere notas particulares en un tiempo donde muchos han decretado o lamentado la eliminación del Estado y su reemplazo por el empoderamiento de la comunidad. Ahora, lejos de esa eliminación, nos encontramos con políticas y la acción del Estado permanentemente en los barrios. Modos que desde ya involucran la policía, pero también otros modos de intervención del Estado. De hecho, el estado es un agente activo de las biopolíticas del ego y del emprendedorismo. Así, en esa línea, a través del trabajo en terreno, ofrecemos elementos que nos permiten describir cómo se viven las políticas del ego proyectadas, construidas y resistidas en la vida del barrio, en el día a día.

Asimismo, lejos de la retórica de las villas (Arabindoo, 2011) y el llamado a potenciar a los sujetos que son evaluados con baja autoestima, nos encontramos en el barrio con una alta voluntad de vida, de insistencia. De este modo, por un lado, las líneas al gobierno de la población que se asientan en el empoderamiento y la comunidad; por el otro, las líneas de fuga que irrumpen a veces de modo silencioso, donde esa agencia de la comunidad involucra otro conjunto complejo de prácticas.

Es en este marco de debates y procurando trazar elementos que contribuyan a describir algunas de las líneas que componen esas biopolíticas. En ese marco recuperamos la experiencia de esas políticas tal como se ensambla en la intersección escuela-barrio en su devenir cotidiano. Como señalamos este artículo se realiza sobre la base un programa de investigación realizada en la intersección escuela-barrio ubicado en la Región Metropolitana de Buenos Aires (Argentina), principalmente en contextos de pobreza urbana extrema. En esa búsqueda nos ocupamos de ese vivir y estudiar en las villas. Organizamos la exposición en torno de tres modulaciones de ese vivir donde una última, en la

1 Si bien el debate en torno a los derechos y las políticas de inclusión amerita un trabajo en sí, cabe recuperar aquí la siguiente referencia de Deleuze y Guattari: "los derechos del hombre son axiomas: pueden coexistir con muchos más axiomas en el mercado - particularmente en lo que a la seguridad de la propiedad se refiere - que los ignoran o los dejan en suspenso o la vecindad impura, decía Nietzsche. ¿Quién puede manterner y gestionar la miseria, y la desterritorialziación-reteritorilización del chabolismo, salvo unos policías y unos ejércitos poderosos que coexisten con las democracias?" (1997, p. 109). 
forma de corolario, creemos que funciona como su fuga y por tanto la presentamos a modo de cierre.

\section{Biopolíticas de la vida urbana: estratos y modulaciones}

En la última clase de Seguridad, territorio y población (2006), Foucault se refiere a una preocupación clave del siglo XVII que remitía a la urbanización del territorio. Ello involucraba un tipo de creación política particular, de regulación del territorio que implicaba la puesta en marcha de modos políticos sobre la vida. La urbe, señalaba, trae consigo una cuestión relativamente novedosa que es la coexistencia densa: cohabitación de los hombres, fabricación de mercancías, venta de productos que pasan a involucrar a la ciudad en sí. Procesos que ocurren verbigracia al calor de la urbanización del territorio que suponía hacer del reino, del territorio entero, una especie de gran ciudad, procurar que el territorio se ordene como una ciudad. Es en este largo proceso que aparece la noción del bienestar, donde instituciones como la policía van a ser llamadas - podríamos decir hoy de un modo un poco paradojal -, a ocuparse de ese bien estar de la población. Como lo describe Rafael ${ }^{2}$ en Utopía, el siglo XV en Inglaterra es testigo privilegiado de ese momento en que la expulsión de los campesinos trae consigo la cuestión del malestar, y de allí la preocupación política/urbana por la regulación de la vida.

Por un lado, es oportuno preguntarse en qué consiste ese bienestar, cuándo se está bien, cuál bien y para quién, y, seguidamente, cómo se ocupa la policía de ese bienestar. Aquí importa retomar estas cuestiones respecto de los modos en que esta mirada se vuelve eje clave de problematización y una de las llaves de la gubernamentalizacion del estado. El cuidado del bien público, ya en esos siglos, aparece como una preocupación por los pobres y los procedimientos asociados a su control. Así, por ejemplo, la exclusión de quienes no podían trabajar y la

2 Rafael, el protagonista de Utopía de Moro, ya en el en silgo XVI, señalaba: “[...] para que un ávido e insaciable glotón pueda cercar y vallar miles de acres de terreno, se expulsa a los campesinos obligados a vender todo e irse como almas pobres y desgraciadas.... se ven obligados a dejar sus casas sin tener lugar a donde ir. Deben vender sus pocos bienes por casi nada y qué cosa pueden hacer más que robar y dejarse ahorcar? Y aún son arrojados a la prisión por vagabundear y no trabajar. Claro que nadie les proporciona un trabajo, por mucho que ellos lo quieran" (2007, p. 60). Como es sabido, este texto es una de los más lúcidos de ese momento en las incipientes sociedades capitalistas; y que influyó en más de un autor. Aquí nos interesa la actualidad del texto, que, incluso con sus matices históricos, no deja de expresar la historia de la pobreza, su gestión, así como la actual constitución de nuestras villas que, en el siglo XXI, no dejan de crecer también al calor de la expulsión campesina. 
obligación de hacerlo se aplicaría a quienes eran aptos para desempeñarse como trabajadores (Castel, 1995, p. 376). Se va a tratar en todos los casos, como lo describe Foucault, "del vivir y el más que vivir, del vivir y el mejor vivir". Ese vivir bien es, en sí, una preocupación urbana que trata de aquellas cuestiones que sólo existen en la ciudad y porque hay ciudad. La salud, la subsistencia, todos los medios para impedir la escasez, la presencia de los mendigos y la circulación de los vagabundos son cuestiones propias de la medicina social que adquieren espesor propio a partir de esa coexistencia densa, que involucra la vida urbana. De forma que, como lo supo describir Foucault (1999), es en esta especial configuración del medio urbano, del milleu, en el que esa población se vuelve categoría, objeto, blanco de poder y saber.

En el siglo XXI, esa gestión política de la vida adquiere especiales tonos donde el giro sobre afectivo constituye un eje clave de las políticas y los debates contemporáneas. Como señala Anderson (2011), la vida afectiva de los individuos y de las colectividades se volvió objeto-blanco de y condición para las contemporáneas formas del biopoder. En esa línea, Rose (2007) refiere a la ethopolítica. En la política de nuestro presente, señala, es posible identificar un particular interés que remite a la conducta de los seres humanos en términos de sus sentimientos, creencias y valores por el ethos de la existencia humana, que se vuelve el medio en el que es posible conectar el autogobierno del individuo autónomo con los imperativos del buen gobierno.

En esas dinámicas, la autoyuda y las lógicas del management - el new public managment como su modo clave -, han permitido ensamblar saberes que ofician como racionalidad de nuestra época, donde la gestión de sí opera como mecanismo de manifestación de la verdad de nuestra época. Gestión de sí que modula como auto-hacerse y el empoderamiento como ingeniería política del ego. Pero, también, como ingeniería que opera en y sobre las comunidades que, como lo discutimos en el siguiente apartado, devienen locus de gestión de las actuales políticas de la vida urbana.

A modo de hipótesis sugerimos que los pliegues del gobierno, los ensamblajes y desensamblajes ocurren tal como aquella modalidad en que el gobierno de los otros involucraba el gobierno de sí (Foucault, 2014); y donde la inversión de la economía de la visibilidad del poder, propias del siglo XVII y del gobierno de los otros, se volvió en la lógica propia de la conducción de la conducta. En el presente, ese gobierno de los otros se plegó sobre el ego. Es en este sentido que la conducción de la conducta actúa sobre el ethos, sobre la vida afectiva en la lógica de un gobierno de sí recargado, donde el gobierno de los otros ocurre como gobierno de $\mathrm{si}^{\prime}$. Las instituciones, comunidades y sujetos son y somos

3 Sobre esta cuestión nos hemos centrado en Grinberg (2015). 
llamados a empoderarnos, revisarnos y rehacernos permanentemente en donde la episteme y tecnologías del management se vuelven saberes clave de esa gestión del self. Gerenciamiento que, en las narrativas de la inclusión (Corcini Lopes, 2013, 2009), se traduce en programas donde la agencia recae en los sujetos y las organizaciones. De hecho, en el caso específico de los slums, es frecuente encontrarse con programas que proponen elevar la resiliencia, actuando sobre autoestimas que se evalúan deprimidas. Ahora, lejos de esas retóricas, nos encontramos en el barrio y en las escuelas con un plus que también discutimos más adelante, también a modo de corolario.

Seguidamente, en el siglo XXI, la cuestión de lo urbano adquiere dos formas que son importantes abordar aquí. En primer lugar, y muy brevemente, ¿qué es emergente y nuevo en la constelación urbana? Se trata de procurar notas para una genealogía situada entre el archivo y el actual.

No se trata de una historia del barrio o de la escuela, sino, más bien, de una genealogía a través de la cual es posible comprender la configuración del actual espacio urbano, los diseños y las redes de relaciones de poder y la distribución espacial de la pobreza extrema en las sociedades contemporáneas.

Por otra parte, en las metrópolis de América Latina, aunque no sólo (Chatterjee, 2008), la pobreza a menudo que enredada con el deterioro ambiental (Davis, 2007; Roy, 2011). Específicamente, en el caso de la educación, las escuelas, muchas veces, no solo son incapaces de salir de este círculo, sino que quedan trágicamente atadas a él. Pobreza y ambiente en los grandes centros metropolitanos, específicamente en el sur global, se ensamblan y configuran en una parte clave de las biopolíticas de la vida urbana. Urbe-ambiente-escuela componen una trilogía sobre la que nos ocupamos aquí ya que configuran parte clave de la posición social de las villas y los sujetos.

Así, por un lado, en el vivir diario de las villas nos encontramos con los estratos de las formas políticas de la vida tal como se sedimentan en la configuración de la urbanidad. Pero también esas estratificaciones involucran modulaciones, no moldes, que hacen a nuestra contemporaneidad. Sobre ello, en tanto que notas metodológicas, nos ocupamos en el siguiente excursus metodológico.

\section{Excursus metodológico sobre modulaciones y estratos}

El trabajo de investigación de tipo etnográfico discutido aquí se desarrolla desde hace más de un decenio, e involucra múltiples etapas y estancias en terreno, en el devenir de la vida barrial y escolar. Aquí retomamos escenas de campo 
que se entrecruzan, ensamblan y rechazan, así como también cómo se afectan en las dinámicas de la vida diaria de una escuela y de un barrio que, entre otros aspectos, dada su posición en la urbe metropolitana, se configuran como uno de tantos espacios del sur global llamados villas, favelas, slums.

Procuramos una analítica de las biopolíticas de la vida urbana en intersección con la vida escolar, atendiendo a las líneas y entrecruzamientos que se producen en la intersección de la cotidianeidad barrial y educacional. En este camino nos encontramos con dinámicas del ejercicio del poder en una mirada que, retomando a Deleuze y Guattari, involucra a lo molar como a lo molecular; las líneas de fuga, pero también con sus reabsorciones. En suma, en ese devenir que comprende la vida barrial, nos encontramos con líneas y estratos, con las lógicas del poder y su contestación.

Dos conceptos adquieren aquí especial relevancia. Por un lado, la noción de estratos que refiere a los fenómenos de espesamiento, acumulaciones, coagulaciones, sedimentaciones y plegamientos a la vez moleculares y molares (Deleuze, \& Guattari, 2004). La conducción de las conductas y las contra-conductas que no conforman dos vértices opuestos de la historia. Desde ya, la vida barrial se configura, se espesa en la historia del capitalismo flexible que, en el mundo globalizado, ha dejado a un conjunto importante de la población compartiendo una misma situación de vida asociada con: la vivienda o su falta, la precarización de las relaciones laborales y la configuración de una población flotante (Foucault, 2007, p. 247), que en el sur global desde fines del siglo pasado ha pasado a vivir en espacios escasa o nulamente urbanizados. Probablemente, las villas constituyen una de las sedimentaciones urbanas más precisas de estos procesos. Ahora bien, la noción de estrato no deja de involucrar una gran movilidad donde una capa sirve de sustrato a otra y sobre la que se producen transcodificaciones, pasos intermedios, mezclas. Así, mientras las villas constituyen una clara sedimentación de las crisis del capitalismo industrial y las configuraciones propias de la sociedad de empresa, los asentamientos involucran sedimentaciones sobre los que operan pliegues y recombinaciones de fuerzas.

A la vez que las villas pueden y suelen leerse entre la victimización y la culpabilización/criminalización, otras líneas se abren cuando uno se acerca al campo y están asociadas a los modos en que las fuerzas molares y moleculares se encuentran, rechazan y actualizan en la vida diaria. Es aquí donde la noción de modulación adquiere un especial interés para nosotros, porque nos permite encontrarnos con modos intermedios, estratos y fuerzas exteriores y, a la vez, con fuerzas intermedias que pujan y también atraviesan a ese exterior. En palabras de Deleuze y Guattari (2004, p. 64): 
Entre lo molecular y lo molar podía haber más o menos estados intermediarios; en la forma. molar podían intervenir más o menos fuerzas exteriores o centros organizadores. Y sin duda, estos dos factores estaban en razón inversa, e indicaban dos casos-límites. Por ejemplo, la forma de expresión molar podía ser del tipo 'molde', movilizando un máximo de fuerzas exteriores o, por el contrario, del tipo 'modulación', haciendo inter-venir sólo un mínimo; no obstante, incluso en el caso del molde, había estados intermediarios interiores, casi instantáneos, entre el contenido molecular que adoptaba sus formas específicas, y la expresión molar determinada desde fuera por la forma del molde. Y a la inversa...

Cabe señalar que no se trata de una fuerza exterior y otra interior que contesta y necesariamente es oposición a esos centros organizados. No se trata de ese tipo de fuerzas. Mucho de ese devenir es resultado de un hacer diario, de un buscarle la vuelta a ese hacer diario de las políticas, las dinámicas glocalizadas de la flexibilidad empresarial. Esas fuerzas moleculares no dejan de ser, muchas veces, más que respuestas de adaptación a aquello molar que es, que ocurre y deja a la gente viviendo en la absoluta precariedad.

La pregunta metodológica que resulta, entonces, es cómo encontrarse con ese hacer que no se constituye en dos extremos, sino en los múltiples puntos que se traman y se abren, se conectan y reconectan. Tal como recuperan los autores de mil mesetas a Simondon, no estamos ante un modelo hilomórfico dos términos definidos o extremidades de una cadena. No se trata de "una simple relación de moldeado bajo la que ya no se puede captar la modulación continua eternamente variable", en el medio, o, más bien entre esos dos extremos ocurre una completa dimensión intermediaria, "todo un espacio propio que despliega su materialidad a través de la materia, todo un nombre propio que extiende sus rasgos a través de la forma (Deleuze \& Guattari, 2004, p. 410). Es esa dimensión, ese intermedio, aquello que uno se encuentra en campo, cuyas líneas se hilvanan y despliegan en ese espacio en donde lo molar y lo molecular se encuentran y rechazan, se moldean y fugan.

Es en este marco en que las nociones de estratos y modulaciones adquieren especial interés metodológico y analítico, acercarse al estudio, al desarrollo de trabajo en terreno es encontrarse con lo molar, aquello que provoca como lo que provoca hacer. Asimismo, ese provocar involucra esas fuerzas moleculares, los contornos, las conexiones, lo disparado y lo que se dispara. Forma y materia se provocan mutuamente, modulan no como dos extremos sino como fuerzas, luchas como multiplicidades heterogéneas. El capitalismo es una máquina axiomática inmanente, señala Chirolla (2005), retomando a Deleuze, que no deja de involucrar agenciamientos concretos de modulación. Las modulaciones son 
inmanentes al capital. El hecho que las "lógicas del control y de las resistencias se entre-crucen no es un defecto es una virtud" (Chirolla, 2005, p. 185). Control y resistencia, en este sentido, son modulaciones, más que extremos de una cadena.

Es en este marco de debates que, procurando trazar elementos que contribuyan a describir algunas de las líneas que componen las actuales formas de la biopolítica de la vida urbana, nos ocupamos de las políticas sobre la vida desde el punto de vista de los estratos y modulaciones de esas políticas en esa intersección que ocurre entre el barrio y la escuela.

\section{Estratificaciones y modulaciones del vivir y estudiar en las villas}

\section{Estamos todos contaminados}

La contaminación, el deterioro del ambiente, la gentrificación y la segmentación urbana constituye una de las notas clave en los debates sobre la cuestión. En muchas descripciones de la vida social, la urbe encarna narrativas de la catástrofe y la fatalidad que, en aras de la sostenibilidad, a menudo, se combinan con la demanda de iniciativa, emprendedorismo y responsabilidad social (Smitha, 2017). La vida aparece como algo que se puede producir resultado de la agencia de una comunidad virtuosa. En estas mismas dinámicas es que, desde fines del siglo XX, se ha ido configurando una retórica de los slums (Arabindoo, 2011), la cual se establece en una unión fundamental entre pobreza y contaminación. Las villas, chabolas, villas, etc. se constituyen en espacios abyectos, zonas de inhabitabilidad, espacios a evitar que funcionan como fantasmas que amenazan al resto de la urbe. En línea con las lógicas del new public management, entre la abyección y el emprendorismo, los barrios más pobres del sur global quedan librados a su suerte y, para sobrevivir, deben asumir la gestión y responsabilidad del barrio, incluso, cuando ello involucra ocuparse de la contaminación, la provisión de servicios públicos o la seguridad. Así, no se trata de poco gobierno o de la ausencia del estado, sino de las formas en que las lógicas gerenciales se presentan en los barrios como una modulación propia de las políticas sobre la vida que involucran también las formas de la presencia del estado en estos espacios de la urbe metropolitana.

La creación del medio, de hecho, fue - y aún lo es -, uno de los campos centrales de intervención biopolítica. Ya desde el siglo XVI no se trataría de la naturaleza y sus condiciones, sino de un medio que es creado, el milleu, articulando tecnologías y saberes que, entre otros aspectos, constituyeron y constituyen, aún, un punto central para la pregunta acerca de la regulación y producción de la pobreza. De hecho, la división del especio urbano entre sectores pobres y 
ricos no constituye un fenómeno sui generis del siglo XXI (Foucault, 2000; Hall, 1996) y encuentra en la criminalización y contaminación uno de los ejes más claros de esa división. En las ciudades de América Latina, con la migración finales del siglo XIX, ocurrió un proceso por el cual los sectores de familias terratenientes que constituían el centro patricio de la ciudad abandonaban sus antiguas mansiones, muchas de origen colonial, en aras de la búsqueda de escapar de las pestes, los contagios masivos y la contaminación. Las ciudades europeas no dejaron de vivir procesos similares. La ciudad de Westminster (Londres), con bastante más larga data, constituye un claro ejemplo de estas dinámicas. Pánicos, miedos son algunos de los estados propios de la vida citadina que han configurado y también marcado el ritmo de las políticas urbanas.

Ahora está claro que, en las sociedades contemporáneas, este tipo de situaciones se solapan y ensamblan de muy diversos modos en tanto aquellos espacios urbanos que, otrora periféricos, han quedado dentro de las metrópolis. Esto es el afuera en el presente. Ha quedado dentro e, incluso, devienen en el interjuego de flujos globales. La urbe metropolitana funciona como cinta de moebius, donde el exterior fluye como parte de un adentro y ello, desde el punto de vista del gobierno, involucra aspectos clave. Así, por ejemplo, la contaminación de arroyos y ríos en las urbes no es algo nuevo; sin embargo, en el sur global, actualmente, se traduce en ciudades donde vivir a la vera del agua se vuelve cada vez más peligroso. Lejos de esos tiempos en que las aguas negras se volcaban aguas arriba, fuera del casco urbano, en nuestros tiempos esas aguas quedaron dentro.

Las diferencias entre estos períodos, y las peculiaridades de cada una son muchas. Pero, hay una cosa que es importante señalar, si, en los procesos y prácticas de gestión de la ciudad, las preguntas ambientales eran una preocupación primordial de la ciencia del estado, ahora estas están atravesadas por las cuestiones de la participación social, la gestión de riesgos, la sostenibilidad y el empoderamiento de la comunidad (Grinberg, Gutiérrez y Mantiñan, 2012). La ciudad emprendedora deja a ciudadanos y comunidades en la ciencia del hacerse.

Es en estas dinámicas, el enunciado "los que vivimos acá ya sabemos que estamos todos contaminados", que nos decía un vecino del barrio, adquiere especial sentido. Se trata de un enunciado, sin duda, trágico, pero también con un increíble sentido de lo práctico. Práctico, en su acepción más cotidiana, pero también como práctica política que entiende del status político de la propia vida. Vivir en las villas, especialmente, para quien ha llegado a radicarse allí, es el resultado de un proceso que involucra varias mudanzas y desalojos, como describía Rafael al asegurar haberse visto obligado ${ }^{4}$ a dejar el lugar donde se vivía

4 Sobre estos procesos tal como se viven en el barrio nos hemos ocupado en Machado, Mantiñan y Grinberg (2016). 
y deambular buscando uno. Así, ese espacio abyecto para quien lo encontró en el barrio, en la villa, deviene un lugar donde construir la casa propia adquiere un doble carácter. Por un lado, el saber que ese es un lugar propio, lugar al que se llega luego de un largo peregrinaje, alejado de cualquier imagen mítica. Es el espacio que se encuentra para hacerse el propio lugar. En esa línea, otro vecino nos decía "carcova es mi lugar en el mundo".

Ahora, lejos del romanticismo que pudiera desprenderse de esta imagen, está claro que se trata de un lugar contaminado. Saberse contaminado es un enunciado práctico, adaptativo, a la vez que político. Pobreza y ambiente se encuentran hace tiempo en la urbe cada vez más de un modo trágico y cruel en la vida de un barrio y sus vecinos. Las situaciones de vida, la complejidad que implica vivir en barrios escasamente urbanizados, salvo que ocurra un desastre e incluso así, la vida suele dirimirse entre acostumbramiento y legalidad de lo ilegal. Ello, en un escenario en el que los sujetos deben hacerse. Ese hacerse deviene en estar siempre en el borde y nunca terminar de caer. Hacerse se traduce, así, en una batalla permanente por mejorar las propias condiciones de vida.

\section{El que no llora no mama: empoderamiento y hacer-se vivir}

La gestión de lo social desde fines del siglo XX se vive entre el decreto o el lamento respecto de la eliminación del Estado y su reemplazo por el empoderamiento de la comunidad. Un llamado generalizado a potenciarnos y a trabajar sobre nuestra cada más frágil autoestima que, por muy diversos motivos, según las hipótesis de la resiliencia, parece ser más baja cuando se trata de los pobres. El gerenciamiento, en tanto que racionalidad de nuestra época, se presenta como auto-hacerse, donde la gestión de sí opera como los mecanismos y modos de la manifestación de la verdad de nuestra época. Desde fines del siglo XX, el gobierno de los otros se plegó sobre el self y la conducción de la conducta aparece como gobierno de sí recargado. Instituciones, comunidades y sujetos son y somos llamados a empoderarse, revisarse y rehacerse permanentemente, en donde la episteme y tecnologías del management se vuelven saberes clave de esa gestión del self. Gerenciamiento en las narrativas de la inclusión (Corcini Lopes \& Hattge, 2009; Corcini Lopes \& Lockmann, 2013) se traduce en programas donde la agencia recae en los sujetos o las organizaciones. De hecho, en el caso específico de los slums es frecuente encontrarse con programas que proponen elevar la resiliencia actuando sobre autoestimas que se evalúan deprimidas. 
La vida del barrio como de la escuela discurre en un constante vaivén donde los sujetos ponen en marcha acciones muy disimiles para garantizar que ocurra aquello que per se debería ocurrir: contar con agua, luz o bancos. El hacer diario se realiza en una permanente administración de sumatorias de detalles que se encuentran en constante estado de desbarrancar. Tanto en el barrio como en las escuelas hay algo que deviene norma que es acostumbrarse a hacer lo que se puede con lo que se tiene o se consigue. Si como señalara Foucault, la biopolítica involucraba hacer vivir y dejar morir, en el presente ese hacer modula como hacer hacer-se vivir. El emprendedorismo, lejos de involucrar una retirada del estado, supone la amplificación de un virtuosismo ciudadano en aras de que la comunidad se vuelva agente de su propio bienestar, o, más bien, de su estar.

Así ocurren particulares modos del hacerse cargo que resultan en una cadena interminable batallas y responsabilidades. De hecho, si la urbanización está presente en estos espacios de la urbe metropolitana suele ser resultado de la acción directa de los habitantes del barrio quienes en una noche realizaron un complejo tendido de agua corriente para todas las casas del barrio (Besana, Grinberg \& Gutiérrez, 2015).

Las metrópolis constituyen uno de los ejemplos más claros de la cristalización de las lógicas gerenciales, incluso, de algún modo, son su paradigma y ello, entre tantos otros aspectos, involucra la profundización de la segmentación urbana. En estas tensiones, el empoderamiento de la comunidad la idea de la ciudad emprendedora deviene tecnología de solución de los problemas de unas urbes fragmentadas. Así es posible identificar instituciones diversas, superpuestas y también difusas, que desarrollan acciones de gestión del bienestar, tanto a nivel de los individuos como de los barrios. Gestiones que, como lo relatan los vecinos, se realizan ante las agencias públicas: "Mañana no voy a estar porque me tengo que ir a La Plata ... estamos averiguando y haciendo trámites para crear una asociación civil para poder presentarnos en los planes del ministerio para recibir fondos..." (entrevista a varón de 50 años).

El hecho que la comunidad se vuelva locus de gestión y gobierno no supone, de ningún modo, la ausencia del Estado y mucho menos ausencia en la conducción de las conductas, como muchas veces suele señalarse. Al contrario, es la forma que ocurre el gobierno. Es la lógica del hacer-hacerse. Ello, especialmente, en los barrios más pobres a través de la distribución de planes y subsidios, la creación de cooperativas o fundaciones transforma a los propios vecinos en gerenciadores, tanto del financiamiento público que llega y atiende los problemas del barrio. Se alienta la autoayuda y las iniciativas locales, de forma tal que el bienestar resulta de la ciudadanía virtuosa. Una nota clave es el constante crecimiento de las ONG con epicentro barrial ya que se han constituido en los caminos a través de los cuales los individuos consiguen fondos, 
planes sociales, micro créditos o subsidios como los caminos alternos para la reproducción. En palabras de los vecinos: "Estoy averiguando para crear una fundación con mi iglesia, así podemos armar un comedor y recibir fondos" (entrevista a varón de 48 años).

Una especial política asociada a la provisión y ampliación de derechos se desarrolla en estos barrios, caracterizada, entre otros aspectos, por posicionar a los sujetos entre la lógica del empoderamiento y del hazte a ti mismo. Tanto la provisión de agua, como de energía eléctrica, la recolección de basura o la mejora edilicia de la escuela se encuentran directamente atadas a esa capacidad de agencia, a la potencia que tienen de gritar y hacerse escuchar, de generar presión en la agenda de gobierno o de establecer vínculos capaces de movilizarla. En estas dinámicas, las escuelas no solo no están exentas de ello, sino que, de muy diversos modos, son el resultado de esa agencia. Los derechos devienen obligaciones que se traducen en una lucha por acceder a aquello que, como ciudadanos per se, se debería acceder.

Como reza el tango "el que no llora no mama" y la escuela, más allá de todos los presagios, se encuentra en mucho mejor estado de aquello que las imágenes asociadas a las villas permiten imaginar. De hecho, más de una vez se han encontrado con quienes llegan por primera vez a la escuela y señalan que "[...] está mejor de lo que imaginaba". Ahora, ese estado de las escuelas tiene más de una arista. Por un lado, aquel que cuando llueve se pregunta si por arriba o por abajo; esto porque el agua se filtra no solo por los techos, sino también por los pisos. Por el otro, ese estar mejor de lo que se espera está asociado con las luchas y agencia de los sujetos. Los equipos docentes viven en ese estado de quien está a la pesca. Maestros y directores viven en la permanente búsqueda de ayuda para encontrar sillas, pinturas, resolver una pared electrificada o baños, que haya puertas en las aulas, etc.; en suma, en un estado permanente de conquista (Bussi, 2013). Escuela y barrio comparten la misma zanja por la carencia o acceso precario a los servicios cloacales, de agua potable, de luz eléctrica, de recolección de basura y por la fragilidad de las viviendas, del entramado de calles y del establecimiento educativo. Como nos decía un dirigente del barrio:

"El fin de semana que viene se pinta la escuela 51. ¿Viste las reuniones de los ministerios? Bueno, ahí se decidió que el fin de semana se va a pintar la 51 y la 40; y el próximo la 50. En realidad, va a ser pintada en varios barrios al mismo tiempo... en Hidalgo también hay... Bueno, Nación pone la pintura y falta la mano de obra; entonces, tenemos que buscar gente para que se anote. Eso sí, hay que anotarse antes del miércoles porque yo paso la lista después. Tenemos que estar anotados 
porque nos van a dar el desayuno y el almuerzo, pero aparte por una cuestión del seguro de la escuela, que como es sábado, ¿viste?... [...] ya te anoto a vos entonces y fijáte si conseguís más gente. No sé, capaz que tus compañeros de la facultad... y me avisas!" (Referente a un Centro comunitario barrial, 16/02/13).

Nos encontramos así con alianzas estratégicas, un estado que oficia como socio (Osborne \& Rose, 1999) y pone la pintura; organizaciones de la comunidad que gestionan la donación y buscan voluntarios para pintar, diciendo que si se anotan reciben el desayuno. Se trata de lógicas de transferencia de la responsabilidad de gestión, las cuales son fundamentales para la comprensión de las actuales políticas de la vida urbana. En la apelación a la solidaridad para pintar la escuela, el estado aparece como un donante que promueve la asociación. Aquello que en realidad es responsabilidad estatal deviene gesta solidaria, compromiso y participación. Tanto el barrio como la escuela quedan en un estar siempre en el borde que genera acciones y actitudes que se dirimen entre una suerte de virtuosismo cívico en el marco de jornadas solidarias y la capacidad que se tenga de gritar, pedir y golpear puertas, sin agotarse o claudicar en el intento.

Ahora bien, esa insistencia, ese estar buscando cómo hacer del barrio y de la escuela un lugar mejor es la otra cara de Jano en la gestión diaria que se realiza sobre la base de la comunidad empoderada. Sin embargo, hay un plus, una tercera modulación que importa resaltar, aquí, a modo de cierre, de corolario.

\section{A modo de corolario: les vamos a ganar por cansancio}

"Les vamos a ganar por cansancio" nos dice un vecino del barrio, mientras se refiere a una de las batallas que mantiene hace años con quienes regentean un basurero ilegal que crece a diario en el barrio, y en un descampado donde niños y jóvenes suelen jugar a la pelota, entre otras cosas y que está emplazado a la vera de una autopista frente a un terreno de la policía. Se trata de un enunciado que expresa con una particular claridad la lucha cotidiana por hacer-se vivir que, a la vez, se vuelve en otro un modo de agencia, de lucha política.

De alguna manera, la imposibilidad de ocuparse de todo en la vida se dirime en un vaivén y son los sujetos o las instituciones quienes, libradas a su propia suerte, deben buscar la forma de hacerse vivir. En la lógica de la vigilancia sindrómica (Fearnley, 2005), muchas veces se trata, justamente, de 
la capacidad de controlar la acción de forma con tal de evitar que esta se salga de carril; dirigirla hacia un fin predeterminado. Así, en el barrio pueden alzarse por años a cielo abierto basureros ilegales, mientras que los vecinos insisten en buscar estrategias para frenar esas prácticas. Estrategias que consiguen ser más efectivas cuando logran interceptar o gritar lo suficientemente fuerte. Un grito que, a veces, debe ser muy fuerte, otras, silencioso y mucho más estratégico. Pero siempre se debe ser insistente y no abandonar la lucha.

Así, luego de un período largo de tiroteos entre bandas a plena luz del día, que entre otros muchos episodios de violencia extrema involucró la matanza de un joven al mediodía, en pleno horario escolar, la escuela quedo haciendo cuerpo a tierra. En ese momento docentes y padres decidieron parar y cerrar la escuela por unos días. Ello con la intención de llamar la atención sobre lo que ocurría hacía meses, procurando alguna respuesta de las autoridades educativas y de seguridad. No se trata aquí de la descripción en sí de lo ocurrido, sino que importa resaltar otra cuestión. En esas dinámicas, una docente con mucha antigüedad me dice "negri, ¿sabés qué pasa si cerramos la escuela? Se la entregamos. Tenemos que estar, que venir, si no nos ganan...”.

En la misma lógica de "le vamos a ganar por cansancio", esta docente estaba preocupada porque si cerraban las puertas, les ganarían; el enemigo, parafraseando a Benjamin, no iba a dejar de vencer. La cuestión es que ese abrir nuevamente las puertas, como de hecho ocurrió, dejó a la institución teniendo que auto-cuidarse y proteger(se) sin, por supuesto, contar con los recursos para hacerlo, ya que las respuestas buscadas simplemente no ocurrieron. La agencia y el auto-protegerse, buscando y aunando esfuerzos, se volvieron la acción certera para no dejarles ganar, pero, a la vez, conseguir algo que le hiciera frente a la fragilidad en que el barrio, la escuela y los sujetos estaban inmersos.

Las luchas cotidianas por la vida son permanentes y muchas veces se presentan como grandes pujas - marchas, piquetes u otros modos -, otras como microprácticas silenciosas; pero, en todos los casos, nos encontramos con un tipo particular de agenciamiento que involucra buscarle la vuelta a una cotidianeidad que es precaria.

Así, no se trata de empoderar comunidades y elevar la resiliencia para que juntos, familias, escuelas, comunidad, etc., consigan sobreponerse a las condiciones adversas; nos encontramos, más bien, permanente con lecciones de cómo verbigracia, esa resiliencia se hace escuela, barrio. Si los sujetos consiguen vivir y reproducir sus vidas cotidianas en las distintas villas miseria, en medio de innumerables microdesprotecciones cotidianas es, justamente, porque tienen una alta capacidad para sobreponerse ante esas situaciones de vida. Y ello no solo vale para los sujetos sino también para las instituciones que deben enfrentar esas mismas situaciones precarias. 
Probablemente es esa insistencia que caracteriza a los sujetos y, especialmente, a los jóvenes, la que hace difícil procesar y comprender la vida escolar y social. Ello, porque ese insistir como forma política es parte clave de modos de producción política de la crueldad cotidiana, donde no hay resiliencia que pueda resolver aquello que es responsabilidad del estado en materia urbana y educativa. De hecho, el reconocimiento de cierta creatividad en quienes viven situaciones adversas constituye parte neurálgica de los modos infames en que las políticas sobre la vida contemporáneas actúan sobre la población.

"Les vamos a ganar por cansancio" se vuelve, de esta manera, clave. Por un lado, tapar los desagües que supone la negación y la abyección, y, por el otro, sujetos luchando en y por el barrio o la escuela, queriendo y deseando. En tiempos en que las crisis han devenido lo más estable, nos encontramos con la lucha insistente y silenciosa por contar con escuelas, por tener un lugar, una casa, un barrio. Lejos de la romantización de esa agencia que podría dar lugar a otra hollywood movie, entendemos que ello constituye parte clave de las modulaciones de la crueldad que presenta la biopolítica contemporánea. Colarse, meterse en los vericuetos, atravesar el laberinto, no abandonar las luchas, en suma, parecen ser los modos en que esa agencia se encuentra con modos silenciosos de lucha en estos tiempos gerenciales, donde insistir es clave para resistir al presente o, sencillamente, para "ganarles por cansancio".

\section{REFERENCIAS}

Anderson, B. (2011). Affect and biopower: towards a politics of life, Transactions, Trans Inst Br Geogr NS 2011, doi: 10.1111/j.1475-5661.2011.00441.x.

Arabindoo, P. (2011). Rhetoric of the 'slum', City: analysis of urban trends, culture, theory, policy, action. Routledge Taylor \& Francis Group, 15 (6), 636-64.

Besana, P., Gutiérrez, R. A. \& Grinberg, S. (2015). Pobreza urbana, comunidad local y Estado-socio en Argentina: la provisión de servicios públicos en un asentamiento de la Región Metropolitana de Buenos Aires. Revista Mexicana de Ciencias Políticas y Sociales, v. 50, n. 225, p. 79-102.

Bussi, E. (2013). Hacer escuela secundaria en barrios de degradación ambiental y pobreza urbana extrema: estudio en torno de los dispositivos pedagógicos en la sociedad del gerenciamiento. Licenciatura en Educación. Universidad Nacional de San Martín.

Butler, J. (2010). Marcos de guerra. Las vidas lloradas. Buenos Aires: Paidos. 
Castel, R. (1995). La metamorfosis de la cuestión social. Paidos: Buenos Aires.

Corcini Lopes, M. \& Hattge, M. (Orgs.) (2009). Inclusão escolar: conjunto de práticas que governam. Belo Horizonte: Autêntica Editora.

Corcini Lopes, M. Lockmann, K. \& Hattge, M. (2013). Políticas de Estado e Inclusión, en, Pedagogía y Saberes, Universidad Pedagógica Nacional, Facultad de Educación, Bogotá, p. 41-50.

Chatterjee, P. (2008). La nación en tiempo heterogéneo. Buenos Aires: Siglo XXI.

Chirolla, G. (2005). Capitalismo y filosofía. una aproximación desde Deleuze, Universitas Philosophica 44- 45, p. 175-186.

Choay, F. (2009). El reino de lo urbano y la muerte de la ciudad, Andamios, v. 6, n. 12, diciembre, p. 157-187.

Davis, M. (2007). Planeta de ciudades miseria. Madrid: Foca.

Dean, M. (2010). Power at the heart of the present: Exception, riskand sovereignty, European Journal of Cultural Studies 13(4) 459-475, Sage.

Deleuze, G. \& Guattari, F. (1997). ¿Qué es la filosofía?, Madrid: Anagrama.

Deleuze, G. \& Guattari, F. (2004). Mil mesetas, España: Pre-textos.

Fearnley, L. (2005). From Chaos to Controlled Disorder: Syndromic Surveillance, Bioweapons, and the Pathological Future. ARC Working Pape, n. 5, March 25.

Foucault, M. (1999). El nacimiento de la medicina social. In Estrategias de poder (Varela y Alvarez Uría (eds.), Madrid: Paidos.

Foucault, M. (2000). Defender la sociedad. Fondo de Cultura Económica, Argentina.

Foucault, M. (2006). Seguridad, territorio y población. Fondo de Cultura Económica, Argentina.

Foucault, M. (2007). Nacimiento de la biopolítica. Fondo de Cultura Económica, Argentina.

Foucault, M. (2009). El gobierno de sí y de los otros. Fondo de Cultura Económica: Argentina.

Foucault, M. (2014). El gobierno de los vivos. Fondo de Cultura Económica: Argentina.

Grinberg, S. (2015). Dispositivos pedagógicos, gubernamentalidad y pobreza urbana en tiempos gerenciales. Un estudio en la cotidianeidad de las escuelas. In Revista Propuesta Educativa Año 24, v. 1, p. 123-130, Junio.

Grinberg, S., Gutiérrez, R. \& Mantiñan, M. (2012). La comunidad fragmentada: gubernamentalidad y empoderamiento en territorios urbanos hiperdegradados. In Revista Espacios nueva serie, n. 7, UNPA, Argentina, p. 154-172. 
Hall, P. (1996). Cities of tomorrow: An intellectual history of urban planning and design in the twentieth century. Oxford, UK: Blackwell Publishers.

Machado, M., Mantiñan, L. M. \& Grinberg, S. (2016). Relatos de infancias: nacer y vivir en las villas del sur global. Cartografía y devenir de la subjetividad en las sociedades contemporáneas. Ultima década, v. 24, n. 45, p. 140-157. https://dx.doi.org/10.4067/ S0718-22362016000200008.

Moro, Th. (2007). Utopía, Buenos Aires: Prometeo.

Osborne, T. \& Rose, N. (1999). Governing Cities: Notes on the Spatialisation of Virtue. Environmental and Planning D: Society and Space, 17, p. 737-760.

Rose, N. (2007). The politics of life itself. USA: Princeton University Press.

Roy, A. (2011). "Slumdog Cities: Rethinking Subaltern Urbanism”. International Journal of Urban and Regional Research, v. 35.2 - Marzo. DOI: 10.1111/j.14682427.2011.01051.x.

Smitha, K. C. (2017). Entrepreneurial Urbanism in India, Singapur: Springer.

Soja, E. (2008). Postmetropolis, Madrid: Traficantes de sueños.

Texto recibido el 11 de julio de 2017. Texto aprobado el $1^{\circ}$ de agosto de 2017. 